\title{
Academic Cheating in School: A Process of Dissonance Between Knowledge and Conduct
}

Andrian Pramadi

State University of Malang,

University of Surabaya

Marthen Pali

Pelita Harapan University

Fattah Hanurawan

State University of Malang

Adi Atmoko

State University of Malang

Doi: $10.1515 / \mathrm{mjss}-2017-0052$

\begin{abstract}
Academic cheating behavior in schools have been discussed and reported. Students display academic cheating behavior during tests, quizzes, or tasks. The dynamics of academic cheating behavior is complex and not easily explained with just one factor. The external factors such as peer influence, teacher's teaching methods, parental pressure, and academic climate are factors that interact with each other to bring out student academic cheating behavior. The grades or numbers from the tests, quizzes, or tasks are used to represent the students' academic performance in school. On junior high school, cheating is already common, generally conducted during tests or quizzes in the form of copying the answers of other students and cooperating on the test. This research is a preliminary quantitative study in the attempt to describe academic cheating behavior on 139 grade XII junior high school students. Sample collection was conducted with "multistage random stratified sampling" or graded/leveled random collection method, which is a sample collection method with population units grouped into homogeneous groups. Research results showed that there were no correlation between students' knowledge of plagiarizing behavior with the behavior appearance $(r=-.0 .096, p=0.260)$ and between knowledge of cheating behavior with the behavior appearance $(r=-0.08, p=0.925)$. However, there was a difference on the appearance of plagiarizing behavior reviewed from the knowledge of plagiarism $(F=2.303, p=$ $0.038)$ while there was no difference on cheating behavior reviewed from the knowledge of cheating ( $F=$ 1.18, $p=0.355)$. This showed that the frequency of students conducting cheating or plagiarizing behavior was not merely based on their level of knowledge.
\end{abstract}

Keywords: academic cheating, cheating behavior, plagiarizing behavior, Process of Dissonance

\section{Introduction}

Academic cheating behavior in schools has often been discussed or reported. Academic cheating is displayed in two forms, including cheating behavior such as coping the answers of others and plagiarizing behavior such as citing a source incorrectly during working on tasks. Students display 
academic cheating behavior during quizzes, tests, or tasks. The dynamic of academic cheating behavior is complex and difficult to explain with just a factor, such as the factor of student. Factors outside the students such as peer influence, teacher's method of teacher, parental pressure, and academic climate are factors that interact with each other in forming students' academic cheating behavior. Academic cheating will be displayed by students during quizzes, tests, or tasks, in which the end result will be numbers (grades). These numbers or grades are used to portray the students' performance in school.

In junior high school, cheating is already common, usually conducted on quizzes or tests in the form of copying the answers of others and working together. Many students already know that cheating behavior during quizzes/tests have prohibited. Meanwhile, the academic cheating in the form of plagiarizing behavior has not yet known by students and it is conducted during written tasks or assignments. In the research conducted by Pecorari (2003), the plagiarizing behavior was often displayed unintentionally. Unintentionally is a reflection of ignorance. The preliminary survey by the research resulted in that almost $90 \%$ of the students knowing that it is cheating but $72 \%$ of them still cheat.

Lately the frequency of academic cheating behavior in junior high school level increases because of the available technological advancements and the opportunity (external factors); and also the pressure to obtain high achievement (internal factor). This is often the justification for cheating or plagiarizing behavior, such as "the teacher did not inform that it was a form of plagiarism" or "the teacher let students cheat and there was no warning". Academic cheating can be viewed in daily academic life in junior high school in Indonesia. In an external context, students cheat or cooperate during tests because teachers/school do not assign consistent and proportionate penalty, therefore making students see it as an open opportunity. The displayed academic cheating behavior eventually became something "commonplace", despite cheating and plagiarizing behavior being dishonest behaviors because it includes "unfair" competition to obtain higher grades without the proportionate effort.

Researchers regarding academic cheating have often been conducted; in America researches started on the year 1941. The phenomenon of dishonest behaviors were displayed with hopes of enforcing honest behaviors in schools, forming academic integrity on academic institutes in America (Pulvers \& Diekhoff, 1999). The researches of cheating and plagiarizing behavior had been conducted for a long time because the behaviors had existed for a long time as well. On the Contemporary Educational Psychology journal in the year 2002, a number of researchers on the frequency of cheating and plagiarizing behavior started on 1941, by Drake to Davis and Ludvison on 1995. Drake et al. on 1941 stated that $23 \%$ of pre-graduate students conducted academic cheating behavior, then on 1960 , Goldsen also stated that $38 \%$ of pre-graduate students conducted academic cheating behavior. On 1989 , Jendrek stated that $40-60 \%$ of pre-graduate students also conduct cheating and plagiarizing behavior. Jendrek on 1992 also stated that there was around $74 \%$ increase in cheating and plagiarizing behavior on pre-graduate students. Graham, Monday, O'Brien, and Steffen on 1994 stated that around 90\% of pre-graduate students conduct cheating and plagiarizing behavior. Followed on 1995 by Davis and Ludvison's research that discovered the frequency of cheating and plagiarizing behavior in high school students, resulting in the finding that more high school students conduct cheating and plagiarizing behavior, concluding that most high school students conduct it (Davis, Drinan, \& Bertram, 2009).

Based on the descriptions from the field researches in America, there was an increase in the frequency (\%) of students conducting cheating behavior. Results on plagiarizing behavior also showed similar results, reviewed from the survey results conducted by the Center of Academic Integrity on 1999 , resulting in $10 \%$ of college students conducting plagiarizing behavior. Results on 2005 showed $40 \%$ college students conducting plagiarizing behavior (Maurer, 2006). Meanwhile on 2010 (Mederich, 2011) from the survey on 40 thousand high school students, it was discovered that $60 \%$ of them cheated during quizzes/tests and it was also discovered that $34 \%$ of them cheated more than twice during quizzes/tests. Regarding plagiarizing behavior, one in three students conducted plagiarizing behavior on sources on the Internet for their assignments. This further reinforces the data that plagiarizing and cheating behavior increased from year to year, in accordance to the advancement of information-related technology. In Indonesia, reports of cheating 
in the level of high school are reported in the mass media in relation to the national exam. This is because the national exam is the determinant for graduation and the grade is used as consideration for university. With such high requirement, students start to conduct academic cheating to overcome the graduation requirements.

As for the relation between cognitive dissonance and cheating behavior, cognitive behavior is the gap between belief with what is conducted or displayed. In this research, dissonance is existent between what have known as something that is prohibited but is still conducted with whatever reason. Festinger (1960, cited in Gire \& Williams, 2007) stated that in a dissonance, an uncomfortable situation happens in which there are two cognitive "contents" opposite of one another. In relation with academic cheating, for example: students feel that the task cannot be completed well or on time and the way to overcome it is by copying other students' work. This is because students know that a task that is not well-made and not completed on time will result in bad grades. Bad grades affect achievement and also the views of parents and peers on students. Therefore the dissonance process is not simplistic because it is related to the "attitude change" on the student.

The researcher viewed that there was a lack of researches connecting the dissonance process with academic cheating. The phenomenon of the emergence of cognitive dissonance on academic cheating would make society understand more about how academic cheating as a complex process.

\subsection{Research Questions}

- Is there a dissonance process on academic cheating behavior, between knowledge and conduct?

- Is there a difference in academic cheating behavior, reviewed from the knowledge level on academic cheating?

\subsection{Research Goals}

- To reveal the relation between knowledge level regarding academic cheating and the frequency of academic cheating in school.

- To observe the difference in majors in high school on the emergence of academic cheating behavior.

\section{Theoretical Review}

\subsection{The Concept of Academic Cheating}

Academic cheating has two forms, which is cheating behavior such as copying answers of others and plagiarizing behavior such as citing without including the correct source. Based on the Encyclopedia of the Social and Cultural Foundation of Education (Provenzo, 2009), plagiarizing behavior includes intentional and unintentional actions in utilizing another person's work wrongly. Plagiarizing behavior is conducted in the form of replicating another person's work, copying the whole text, or even buying another person's writing and then admitting it as one's own. So the plagiarizing behavior is an inaccurate and non-thorough behavior in quoting, citing, and reporting the source being used dishonestly. Based on the Encyclopedia of Applied Psychology (Spielberger, 2004), the definition is similar, plagiarizing behavior is a failure on the writing in citing and referencing source in the writing correctly.

Regarding cheating behavior, the researcher referred to the Encyclopedia of Educational Psychology (Salkind, 2008), which was a dishonest action with the element of deceiving with the goal of obtaining benefits or superiority from other students. Then based on Psychology of Classroom learning, An Encyclopedia (Anderman, 2009), academic cheating behavior is generally displayed in four categories: information transfer between individuals, the use of assisting tools, exploitation of weakness, and copying answers or information. Commonly, cheating behavior is conducted in two activities, which are during tests/exams and homework. 
Based on the depiction of the meaning of cheating and plagiarizing behavior, academic dishonesty behaviors have divided into two kinds: cheating and plagiarizing behavior. This behavior can be intentional or unintentional with the goal of obtaining better grades. The researcher will explain the relation between variables or conditions that result in cheating or plagiarizing behavior.

Cheating and plagiarizing behavior is not a planned behavior by students when they enter an educational institution. It is also not a hereditary nature (Lathrop \& Foss, 2005). The behavior appears because of the number of pressure related to achievements and the fear of failure.

If in the individual factor the person is afraid of failing and the motivation is external (parental pressure/wanting to graduate), then the person may not conduct cheating or plagiarizing behavior if there is no opportunity. The opportunity to be dishonest will be stronger if there are other factors, such as situational factors such as peer that conduct cheating or plagiarizing behavior successfully and not penalized by teachers/institution, or even ignored. The combination of problems on the individual factor (fear of failure or external motivation) with situational factors (peer doing the conduct) and light penalties or inconsistent rules (factors of teacher/institution) and parental pressure with high workload (classroom context) result in an attitude to cheat or plagiarize.

The attitude to cheat or plagiarize will become a behavior or conduct that can be intentional or unintentional because of three factors in attitude, which are on adaptation, ego-defense, or selfexpression. In this research, the researcher has reviewed the attitude in the frame of adaptation on the pressure of achievement or school. When students cheat and they do not know that the action is cheating behavior, then it is unintentional. If the students know and they still conduct it, then it is intentional.

On previous research by McCabe, 1999 (Hutton, 2006), students believed that dishonest or cheating behavior in school were alright because they saw the school doing nothing towards the behavior. This became a justification on cheating or dishonest behavior in school. The conclusion happened because of external or situational factors enabling students to conduct the behaviors at school.

\subsection{Cognitive Dissonance}

According to Festinger (1957, cited in Gire \& Williams, 2007), cognitive dissonance is the discrepancy between two inconsistent cognitive elements, causing psychological discomfort or anxiety, and motivating someone to act to reduce the dissonance. The element of the dissonance is cognitive. In relation to cheating behavior, the cognitive element is knowing that cheating or plagiarizing behavior is prohibited by the other cognitive element show that there is a higher risk or damage if the cheating or plagiarizing conduct is not followed through. The other cognitive elements are situation or conditions of peers that are open and opportunities to do the conduct.

Every dissonant relation is not similar in substance, and Festinger (cited in Gire \& Williams, 2007) stated that the importance level of the cognitive elements affect the magnitude of the dissonance. The more important or valuable a cognitive element, the magnitude of the dissonance relation between elements will be.

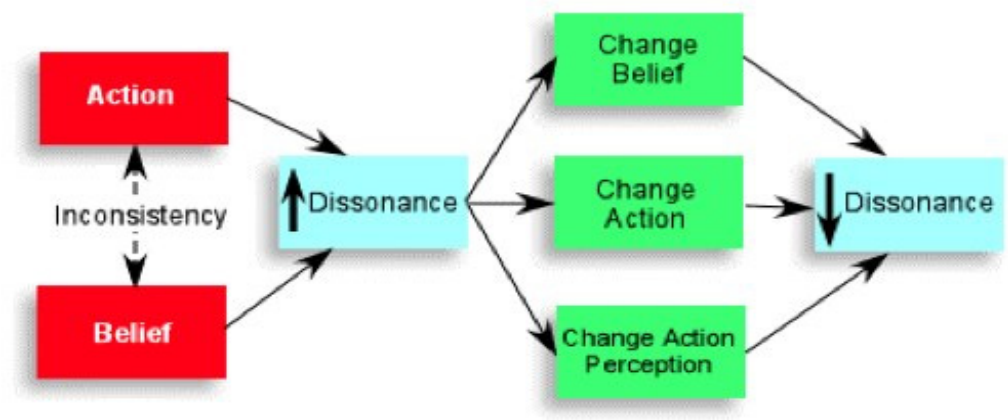

Figure 1: The Dynamics of Cognitive Dissonance (Festinger \& Carlsmith, 1959) 
Based on the Figure, there are three assumptions in cognitive dissonance, which is basically humans being susceptible to inconsistency between belief and action, and the inconsistency cause dissonance and the attempt to overcome it; the dissonance is overcame with three methods, which are: changing belief, changing action, or changing action perception.

\section{Research Method}

\subsection{Instruments and Variables}

This research used quantitative, non-experimental approach; with causality correlational research design. The first research design inspected the causality between variables. There were four research variables with the instrument Academic Practices Survey:

- Cheating behavior variable: how often students cheat, such as copying answers and cooperating and not reporting the higher grades from cheating. The score range is 1 (never) to 6 (always).

- Plagiarizing behavior variable: how often students plagiarize, such as citing or taking several sentences without including the sources. The score range is 1 (never) to 6 (always).

- Cheating behavior knowledge level (cheating \& plagiarism). This is measured by using a number of statements, researcher have used 7 item and subjects were asked to grade them as a plagiarism or not $($ Yes $=1 \&$ No $=0)$. The total score are from 0 to 7 .

- High school majors variable.

Quantitative research design was chosen because the researcher collected data in the form of ordinal and interval data's from a large number of samples. The research was non-experimental because the researcher did not try to manipulate the relation between existing variables and aiming to discover the influence between the predictor and criterion variables.

\subsection{Population and Sample}

The populations of this research were high school students of the " $X$ " Catholic high school in Malang Indonesia with the accreditation grade of $A$. The high school was chosen because of the adequate learning facilities and disciplinary rules and high consistency towards violations of school rules. The research subjects were students of class XII.

Sample collection was conducted using the multistage random stratified sampling technique, which is a sample collection technique by population units grouped into homogenous groups. This was conducted by randomly taking 2 "science classes", 2 "social science classes", and 1 "language class" from the XII class. At the end, the total samples were five classes from the population of the whole school with at least 150 students as the sample. In this research, only 139 students were complete in giving their data.

\section{Research Results}

\subsection{Frequency Data}

Table 1: The Score of Plagiarism, Cheating, and Knowledge Level Scores.

\begin{tabular}{|l|c|c|c|c|}
\hline \multirow{2}{*}{$\mathrm{N}$} & Score Plagiarism & Score of Cheating & Knowledge of Plagiarism & Knowedge of Academic Cheating \\
\cline { 2 - 5 } & 139 & 139 & 139 & 139 \\
\hline Mean & 3.3957 & 3.0935 & 3.7914 & 5.6043 \\
\hline Median & 3.0000 & 3.0000 & 4.0000 & 7.0000 \\
\hline Mode & 3.00 & 3.00 & 4.00 & 7.00 \\
\hline Std. Deviation & .98994 & .88377 & 1.72145 & 1.87902 \\
\hline Minimum & 1.00 & 1.00 & 1.00 & 1.00 \\
\hline Maximum & 6.00 & 6.00 & 7.00 & 7.00 \\
\hline
\end{tabular}


Table 2: The Score Comparisons of Plagiarizing and Cheating Behavior

\begin{tabular}{cccc}
\hline Score Cheat & Frequency & Percent & Cumulative Percent \\
\hline 1.00 & 4 & 2.9 & 2.9 \\
2.00 & 26 & 18.7 & 21.6 \\
3.00 & 71 & 51.1 & 72.7 \\
4.00 & 30 & 21.6 & 94.2 \\
5.00 & 7 & 5.0 & 99.3 \\
6.00 & 1 & .7 & 100.0 \\
Total & 139 & 100.0 & \\
\hline \multicolumn{5}{r}{} & & \\
\hline Score of Plagiarism & Frequency & Percent & Valid Percent \\
\hline 1.00 & 6 & 4.3 & 4.3 \\
2.00 & 12 & 8.6 & 8.6 \\
3.00 & 62 & 44.6 & 44.6 \\
4.00 & 40 & 28.8 & 28.8 \\
5.00 & 18 & 12.9 & 12.9 \\
6.00 & 1 & .7 & .7 \\
Total & 139 & 100.0 & 100.0 \\
\hline
\end{tabular}

Table 3: The Comparison of Plagiarizing and Cheating Behavior Knowledge Levels

\begin{tabular}{cccc}
\hline Knowedge of Plagiarism & Frequency & Percent & Valid Percent \\
\hline 1.00 (POOR) & 17 & 12.2 & 12.2 \\
2.00 & 15 & 10.8 & 10.8 \\
3.00 & 29 & 20.9 & 20.9 \\
4.00 & 33 & 23.7 & 23.7 \\
5.00 & 19 & 13.7 & 13.7 \\
6.00 & 16 & 11.5 & 11.5 \\
7.00 (Excellent) & 10 & 7.2 & 7.2 \\
Total & 139 & 100.0 & 100.0 \\
\hline \multicolumn{4}{c}{} \\
\hline Knowled of Cheating & Frequency & Percent & Valid Percent \\
\hline 1.00 (POOR) & 9 & 6.5 & 6.5 \\
2.00 & 6 & 4.3 & 4.3 \\
3.00 & 5 & 3.6 & 3.6 \\
4.00 & 14 & 10.1 & 10.1 \\
5.00 & 15 & 10.8 & 10.8 \\
6.00 & 18 & 12.9 & 12.9 \\
7.00 (Excellent) & 72 & 51.8 & 51.8 \\
Total & 139 & 100.0 & 100.0 \\
\hline
\end{tabular}

Based on the comparison between scores and knowledge levels, descriptively it is shown that the students were quite knowledgeable about plagiarizing and cheating behavior with the score average of above 3.5 (in a scale of 1-7), while the frequency of behavior scored around 3 (in a scale of 1-6), meaning the students occasionally conduct academic cheating.

\subsection{Statistical Test Results}

Table 3: Results of Correlation Test Between Academic Cheating Behavior and Knowledge Level

\begin{tabular}{lcc}
\hline & Knowledge of Plagiarism & Knowledge of Cheating \\
\hline Cheating Score & $(r=-0,096, p=0.260)$ & $(r=-0.08, p=0,925)$ \\
Plagiarism Score & & \\
\hline
\end{tabular}

The result in table 3 showed that there was no relation between knowledge level of plagiarizing and cheating behavior with the behaviors in class. 
Table 4: The Significance of ANOVA Test Result Between Variables.

\begin{tabular}{lccc}
\hline & & Social & Language \\
\hline Skor Cheat & Science & $p=0.354$ & $p=0.028^{*}$ \\
Skor Plagiat & Language & $p=\mathbf{0 . 0 0 1}^{*}$ & $X X X X$ \\
& Science & $p=0.727$ & $p=0.993$ \\
Know Cheat & Language & $P=0.889$ & $X X X X$ \\
& Science & $p=.054$ & $P=0.273$ \\
Know Plagiat & Language & $p=.977$ & $X X X X$ \\
& Science & $p=969$ & $p=0.233$ \\
\hline
\end{tabular}

The result on that table, shows that there was a significant difference between cheating behavior on students on class of science major with class of language major and class of social major with class of language major. But between class of science and class of social majors there was no significant difference.

\section{Conclusion and Discussion}

\subsection{Discussion}

No relation between knowledge level and plagiarizing and cheating behavior showed that academic cheating behavior emerge regardless of whether students had the knowledge or not. Once more, this showed that academic cheating behavior is multifactorial. This means that a lot of factors can be the predictor of cheating behavior. This research result rejected the previous result from Pecorari's research (2003) that stated that plagiarizing behavior was often displayed unintentionally because of no knowledge regarding plagiarizing behavior.

In this research, the students of class XII were quite knowledgeable about plagiarizing and cheating behavior but they still conducted it. This meant that there was cognitive dissonance, the discrepancy or inconsistency between belief/knowledge and conduct. According to Festinger and Carlsmith (1959), the dissonance happened because of the inconsistency of social environment in reacting to the actions that contradict the belief.

Referring to McCabe's research on 1999, it seemed that the students believed that dishonest behavior in school were alright because they saw the school doing nothing (not giving penalties) on the behavior. This became a justification that dishonest behavior was alright. There were other factors aside from knowledge (individual), such as external and situational factors that enabled student to do the dishonest conducts.

\subsection{Conclusion}

When situational factor (peer and risk), contextual factor (class, teacher, parents, institute) meet with individual factor, this will increase the opportunity for individuals to cheat or plagiarize. Based on the results of previous researchers, academic dishonesty behavior was not simply related to individual factor but was a combination with situational factor. This reinforced that individual factor cannot become the only predictor in cheating and plagiarizing behavior. Even so, situational or contextual factor cannot be the only predictor as well. Therefore, the school should not just reinforce the individual factor (knowledge level) but also situational factor (teaching model) and external factor (scientific climate and consistency of penalty).

\section{References}

Anderman, E.M., (Ed). 2009. Psychology of Classroom Learning An Encyclopedia. Macmillan Reference USA, a part of Gale, Cengage Learning

Ajzen, I. (1991). The theory of planned behavior. Organizational Behavior and Human Decision Processes, $50(2), 179-211$. 
Bandura, A. (1986). Social foundations of thought and action. Englewood Cliffs: NJ Prentice-Hall.

Buckley, M. R., Wiese, D. S., \& Harvey, M. G. (1998). An investigation into the dimensions of unethical behavior. Journal of Education for Business, 73(5), 284-290.

Davis, S., Drinan, P.F., Bertram, T. 2009. Cheating in School : What We Know and What We Can Do. West Sussex. Wiley-Blackwell.

Festinger, L. \& Carlsmith, J. M. 1959. Cognitive consequences of forced compliance. Journal of Abnormal and Social Psychology, 58, $203-210$.

Gire, G.T \& Williams T.D, 2007. Dissonance and the Honor System: Extending the Severity of Threat Phenomenon. The Journal of Social Psychology, 147(5), 501-509

Granitz, N. and D. Loewy: 2007, 'Applying Ethical Theories: Interpreting and Responding to Student Plagiarism', Journal of Business Ethics 72(3), 293-306.

Hutton, P.A (2006). Understanding student cheating and what educators can do about it. College Teaching. 54 (1) $171-176$.

McCabe, D. L. and L. K. Trevino: 1993, 'Academic Dishonesty: Honor Codes and Other Contextual Influences', The Journal of Higher Education 64(5), 522- 538

McCabe,D.L. \& Trevino, L., \& Butterfield, K.D. 1999. Academic integrity in honor code and non-honor code environments: A qualitative investigation. The Journal of Higher Education, $70: 211-234$.

Pecorari, D. 2003. Good and original: Plagiarism and patchwriting in academic second language writing. Journal of Second Language Writing 12: 317-45.

Pulvers, K., \& Diekhoff, G.M. (1999). The relationship between academic dishonesty and college classroom environment. Research in Higher Education, 40, 487-498.

Spielberberger C. (Ed). 2004. Encyclopedia of Applied Psychology. Elsevier.Inc

Salkind, Neil J. (Ed). 2008. Encyclopedia of Educational Psychology. California. SAGE Publications, Inc.

Trevino, L. K., \& Youngblood, S. A. (1990). Bad apples in bad barrels: A causal analysis of ethical decisionmaking behavior. Journal of Applied Psychology, 75(4), 378-385. 